DOI: https://doi.org/10.14232/actahisp.2021.26.151-156

\title{
GOTAS DE ORO. NACIMIENTO DE UN CONTINENTE MULTIFACÉTICO
}

\author{
MARCEL NAGY \\ Investigador independiente, Hungría \\ Jancsó, Katalin (2021): Aranycseppek Latin-Amerikában. Egy sokszínü kontinens születése \\ [Gotas de oro en Latinoamérica. El nacimiento de un continente multifacético]. \\ Szeged: SZTE Press, 292 páginas. \\ ISBN (impresa) 978-963-306-800-7, ISBN (pdf) 978-963-306-806-9 \\ DOI: https://doi.org/10.14232/sztep.jk.2021
}

El peruano Francisco García Calderón aseguraba de una manera idealizante en La creación de un continente (1912) que "tierra de inmigraciones ideales y materiales, es la América un mundo en formación. [...] Colinas y montañas ciclópeas, desiertos como el Sahara y florestas de abrumadora fecundidad, hombres del Cáucaso y de Oriente, africanos e indios, todo se armoniza en la vasta patria multiforme" (García Calderón, 2001: 246). A pesar de que la inmigración (o migraciones) latinoamericana fue uno de los temas que más inquietaron a muchos pensadores, políticos e historiadores a lo largo de los últimos siglos, muy pocos han intentado relatar su historia "general", tal vez por su complejidad. La historiadora y profesora del Departamento de Estudios Hispánicos de la Universidad de Szeged, Katalin Jancsó, ha encarado esa tarea y nos narra en casi 300 páginas la historia de la migración en América Latina, en un tomo informativo y entretenido al leer, pero difícil de reseñar, debido a la cantidad de informaciones, datos, citas y referencias que ofrece. El texto hace un recorrido que abarca la historia del subcontinente desde la colonización, por las dinámicas migratorias que afectaron el desarrollo social de Latinoamérica y que determinaron no solo las culturas de cada uno de los países del continente, sino también la latinoamericana como una unidad de carácter propio y auténtico. En este recorrido la autora cuenta la historia moderna de América Latina desde el punto de vista de las migraciones y los migrantes.

Katalin Jancsó define cuatro etapas de los movimientos de población en América Latina: primero desde la conquista hasta la independencia, el segundo capítulo es el de la inmigración masiva, que abarca las últimas décadas del siglo XIX y primeras del XX. Es en estos años cuando países como Argentina, Brasil o Uruguay registraron un importante crecimiento de su población. La tercera fase comenzó en la década de los 1930 y duró hasta mediados de los sesenta, cuando el proceso de urbanización se aceleró, promoviendo la migración interna. La cuarta etapa comenzó en las últimas décadas del siglo XX, con un importante flujo 
migratorio desde el subcontinente hacia el extranjero, principalmente hacia los países más desarrollados.

El tomo se divide en cuatro unidades más grandes, la primera introduce al lector en el tema en general, aclara los términos básicos como migración e inmigración, cuáles son los factores push y pull (que motivan a la gente a abandonar un territorio determinado) y asegura que los movimientos de personas "es uno de los importantes y siempre presentes motores de la historia de la humanidad". Jancsó también define las diferencias entre la inmigración voluntaria o forzada con el ejemplo del sistema incaico de desterrar, dentro del imperio, a los pueblos subyugados o con el del abandono de sus respectivas patrias de los judíos europeos desde la década de 1930. Otros factores que ayudan la clasificación de la migración es su duración, o sea, si es indefinida, para siempre, o -por ejemplo- para una temporada de cosecha, o si se realiza en grandes grupos o a solas. La investigadora también recoge las causas que motivan hasta el día de hoy a las personas a que abandonen su país o región, que son muy amplias: desde las políticas, hasta las económicas o medioambientales, entre muchas otras.

La segunda unidad del libro ofrece un contexto histórico, dividido en tres subcapítulos ("Los inicios", "La era de las grandes inmigraciones" y "Después de la Primera Guerra Mundial"). En esta unidad se analizan las diferencias que hubo entre las políticas de migración de la Corona española y la portuguesa. El reino de España en un primer instante intentó -en vano- prohibir que extranjeros viajaran a los territorios de ultramar, mientras que Portugal fue más permisivo en este terreno. En el siglo XIX los países ya independientes de América Latina se integraron en el mercado mundial como suministradores de materias primas lo que requería manos de obra, más aún después de las leyes de abolición de la esclavitud. La historiadora ofrece muchos ejemplos de cómo los países del subcontinente reaccionaron e intentaron atraer a cada vez más extranjeros. En Perú, por ejemplo, ya en 1822 decretaron que, si un extranjero se instala en el país para realizar actividades científicas, artísticas o comerciales, se convierte automáticamente en ciudadano si presta juramento a la independencia de Perú. Brasil en estos tiempos buscaba mano de obra para trabajar en las plantaciones, mientras que Argentina quería poblar su extenso territorio. Las leyes relacionadas con la inmigración describían bien los problemas económicos que encaraban estos países. Hasta los años 1930 la inmigración masiva afectó a países como Argentina, Brasil, Uruguay, Chile, México y Cuba, pero fueron las costas atlánticas y la región de La Plata (o sea Buenos Aires y Montevideo) que "para las primeras décadas del siglo XX ofrecieron una imagen étnicamente multicolor con variadas culturas y religiones, donde el mestizaje seguía siendo un componente determinante", afirma Jancsó. Esta etapa de inmigración en grandes cantidades se quebrantó con la crisis de 1929 y como consecuencia los países se encerraron, muchos de ellos con leyes que prohibían o limitaban la entrada de extranjeros. 
La tercera parte de la monografía describe las grandes tendencias de movimiento de personas de diferentes partes del mundo que afectaron a América Latina. Katalin Jancsó prosigue con la descripción de los casos concretos de grupos étnicos o países y regiones que para hoy se han convertido en importantes elementos de la civilización y cultura latinoamericanas. El caso de los africanos se diferenció de los demás por su carácter inhumano y violento. Como se pregunta Mária Dornbach en su libro sobre la santería cubana y en relación con los esclavos africanos que llevaban a América: ¿qué otra cosa habrían podido llevar consigo sino lo que les cupiera en la cabeza?" (Dornbach, 1993: 11). La mezcla de culturas ya comenzaba en las embarcaciones donde los africanos estaban encerrados junto a otros de diferentes países y regiones de África. Más tarde, ya en América, la evangelización forzosa tampoco pudo erradicar del todo la cultura que los africanos llevaban en sus recuerdos y de a poco surgieron las religiones sincréticas que en la superficie seguían el culto cristiano, pero por debajo ocultaban elementos africanos. Unos 9,5 millones de africanos fueron llevados contra su voluntad a América durante los 355 años que pasaron entre la primera y última embarcación (1518-1873). Los países que dieron el núcleo de Afroamérica fueron los de grandes plantaciones, los actuales Brasil, Cuba, Venezuela y Puerto Rico, donde el sistema esclavista colonial no contaba con suficiente mano de obra indígena, apunta la autora. En el subcapítulo que trata el tema de los africanos en América en los siglos XIX y XX, Katalin Jancsó hace un repaso de los procesos sociales y políticos de los que fueron protagonistas los negros en el continente. Aquí hay que destacar que en la década de los 1880, en Brasil, donde ya se publicaban varias revistas que funcionaban como "un espejo para mostrar a los brasileros las humillaciones que sufrían los africanos y mulatos". Es un dato interesante que ya en esta década en estas superficies se abandonó el uso del vocablo "negro" por su connotación negativa y proponían aplicar el término de "personas de color".

El próximo capítulo analiza la emigración europea hasta la Primera Guerra Mundial, cuando la llegada de (principalmente) europeos dio un impulso de crecimiento demográfico antes no experimentado y que cambió sustancialmente las sociedades de la costa atlántica, pero también de países como Chile. Europa fue testigo de un aumento incontrolable de su población, generando múltiples desafíos, por lo que entre 1830 y 1930 más de 50 millones de personas decidieron abandonar el viejo continente. Esta fue la etapa de la inmigración hacia América Latina más analizada. Los volúmenes de crecimiento demográfico alcanzaron extremos como el de Argentina, cuya población se multiplicó por doce entre 1869 y 1960. Es destacable, como señala Katalin Jancsó, que la gran parte de esta migración se concentró en ciudades, lo que significó el fracaso (parcial y temporal) de las políticas de poblar los territorios baldíos, frente a lo sucedido en los Estados Unidos, donde esta meta fue lograda con más facilidad. La autora hace un recorrido por los países europeos y analiza cómo las comunidades se han acomodado en el 
nuevo ambiente. También destaca las diferencias que explican muchos fenómenos sociales, como por ejemplo que en general los inmigrantes ingleses o alemanes conservaron más su identidad que los franceses. Un importante legado inglés en América Latina fue y es el del fútbol que los países conocieron desde mediados del siglo XIX, y que como subraya la autora, en sí se ha constituido como un elemento importante de muchas identidades locales, basta en pensar en Argentina o Brasil, entre otros. Los emigrantes rusos, por ejemplo, jugaron un papel importante en el desarrollo de la vinicultura de Baja California, mientras que los alemanes y holandeses fueron los que propagaron la cultura de consumir cerveza en muchos países del subcontinente.

Los países que más emigrantes emitieron a finales del siglo XIX y las primeras décadas del XX fueron primero Italia y posteriormente España, así como Portugal. Sabemos que actualmente en países como Argentina o Uruguay la población es mayoritariamente descendiente de españoles e italianos, que indudablemente han formado substancialmente la identidad, cultura, economía y sociedad de la región. El clima de estos países (principalmente Argentina, Uruguay, Brasil y Paraguay) hizo que muchos italianos eligieran estos países como su nueva patria, que al situarse en las costas atlánticas eran más fáciles de acceder. "La emigración en masa italiana inició en 1885 [...] su mayoría se instaló en Buenos Aires y Montevideo”, afirma Jancsó y agrega que estos inmigrantes llevaron a su nueva patria una cultura multicolor e ideas políticas de un amplio abanico (anarquistas, socialistas, liberales, republicanas) que juntos influyeron en el desarrollo político y cultural de la sociedad argentina. Uruguay en estos años se convirtió en el país latinoamericano más "europeo" ya que casi toda su población era de origen europeo. En el caso de Italia y España el texto no solo analiza los datos nacionales en un conjunto, sino que ofrece una revisión de las tendencias migratorias regionales y así nos enteramos, para dar un ejemplo, de que entre 1885 y 1930 unas 900.000 personas abandonaron Galicia para cruzar el océano hacia Latinoamérica. Más allá de las tendencias ya mencionadas, durante la Segunda Guerra Mundial los Estados Unidos veía con recelo la emigración alemana, italiana y japonesa hacia el subcontinente y pidió a sus aliados del sur que expulsaran a los ciudadanos de esos países, que reaccionaron a la petición con un entusiasmo moderado, ya que sus intereses económicos eran otros. Es bien sabido que muchos nazis se escaparon de la justicia después de la Segunda Guerra Mundial emigrando principalmente hacia países de América del Sur (Argentina, Paraguay, Uruguay, Brasil), pero se sabe menos sobre el caso mencionado por Jancsó de los ustachas croatas que también se refugiaron en Argentina.

Una de las partes más informativas del libro para los lectores europeos es la que trata la emigración no europea, como la china, japonesa, coreana, india, del Oriente Próximo, así como la del "pueblo invisible", o sea, de los gitanos. Es aún más difícil reseñar estos capítulos ya que ofrecen un sinfín de informaciones útiles y novedosas. Respecto a los chinos que llegaron al continente, principalmente a Perú, 
Cuba o México hay que destacar que primero fueron tratados como esclavos en plantaciones, pero en todos los países han dejado huellas importantes en la cultura local, como el Barrio Chino de La Habana antes de la revolución, o en la gastronomía peruana, hoy reconocida como una de las mejores del mundo. En relación con Japón es importante mencionar que el Gobierno nipón contaba desde su apertura hacia el mundo después de una autarquía de siglos, a finales del XIX- con importantes estrategias de emigración y, por ejemplo, en 1893 el Ministerio de Asuntos Exteriores mandó una delegación a México para que analizara las posibilidades de asentamiento en los estados de Guerrero, Chiapas y Oaxaca. Las relaciones con los países latinoamericanos, aliados de EE.UU. han empeorado durante la Segunda Guerra Mundial, pero posteriormente la presencia japonesa se hizo cada vez más importante en la economía, y en el caso de Perú hasta en la política, donde en las elecciones de 1990 ganó Alberto Fujimori, cuyos padres habían llegado al país desde Japón en 1934.

El estudio de los casos concretos se completa con los de los marroquíes, turcos, persas, libaneses, armenios y otros de la región de Oriente Próximo, cuya presencia es menos visible, pero igual así no deja de ser importante. En relación con los judíos la historiadora recuerda que, a pesar de las prohibiciones de la Corona, durante la Colonia muchos conversos llegaron a América Latina. Actualmente en Latinoamérica viven unos 500.000 judíos, más de la mitad en Argentina, donde se ha formado la comunidad más grande del continente. Respecto a los gitanos se cuenta con pocos datos, pero como recuerda Jancsó, ya en el tercer viaje de Colón en 1498 en el registro aparecían cuatro "egipcios", Antón, Catalina, Macías y María que probablemente eran gitanos españoles. Un dato interesante es que en Latinoamérica hasta el momento solo Colombia ha reconocido a los gitanos como minoría.

El último capítulo del texto central es un epílogo que propone varias direcciones de investigación en lo que se refiere a la migración interna en el continente de las últimas décadas y hasta nuestros días. La pobreza, la violencia, las dictaduras siguen siendo importantes causas de emigración y América Latina ha sido testigo de muchos casos después de 1960. La inseguridad causada por las guerrillas de Colombia, principalmente las FARC, fueron un importante factor que empujó hacia al extranjero a 5,7 millones de colombianos. En la vecina Venezuela en los últimos años se ha registrado una de las emigraciones en masa más importantes y solo en 2018 más de un millón de venezolanos cruzaron las fronteras hacia Colombia huyendo de la inseguridad. La solución no está dada y según la historiadora no habrá cambios hasta que los países del continente logren un desarrollo a largo plazo, con estabilidad dentro del marco de la democracia sólida, con la erradicación de la violencia, la pobreza, la desigualdad y la corrupción. Igual así fueron todos esos procesos de dos o tres siglos que han hecho de América Latina una de las regiones étnicamente más diversas del mundo, con ciudades cosmopolitas y vibrantes como São Paulo o Buenos Aires. 
Gotas de oro. Nacimiento de un continente multifacético

La autora ha consultado una bibliografía más que abundante, dando una base sólida a lo expuesto en cada uno de los capítulos del libro, apoyándose también en un material gráfico interesante y relevante.

Katalin Jancsó ha agregado una importante gota de oro a la historiografía húngara sobre América Latina con un tomo que seguramente será un libro de texto

imprescindible en las universidades de Hungría. Merecería ser traducido a otros idiomas.

\section{Referencias bibliográficas}

García Calderón, Francisco (2001). Obras escogidas: La creación de un continente. Lima: Fondo Editorial del Congreso del Perú.

Dornbach, Mária (1993). Orishas en soperas. Los cultos de origen yoruba en Cuba. Szeged: JATE. 